\title{
LIFECYCLE VERIFICATION OF TANK LINER POLYMERS
}

\author{
D. Barton Smith \\ Energy and Transportation Research Division \\ Lawrence M. Anovitz \\ Chemical Sciences Division
}

Date published: March 2014

Prepared for

DOE Office of Energy Efficiency and Renewable Energy

Hydrogen and Fuel Cells Program

Storage Subprogram

Prepared by

OAK RIDGE NATIONAL LABORATORY

Oak Ridge, Tennessee 37831-6285

managed by

UT-BATTELLE, LLC

for the

U.S. DEPARTMENT OF ENERGY

under contract DE-AC05-00OR22725

Approved for public release:

distribution is unlimited. 


\section{CONTENTS}

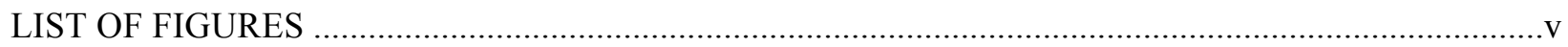

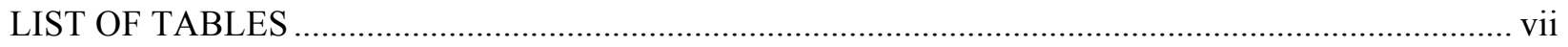

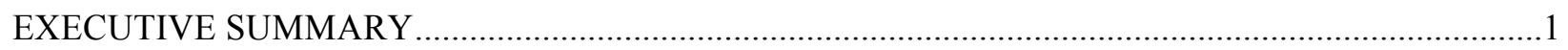

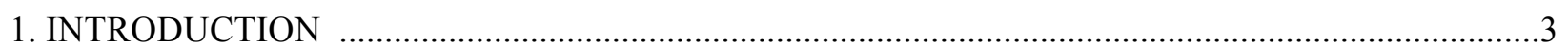

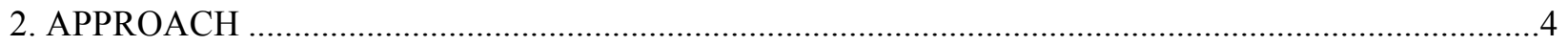

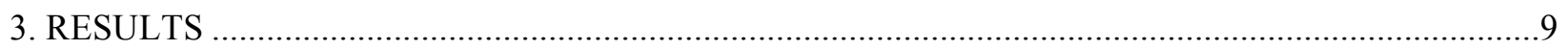

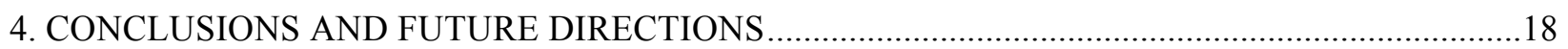




\section{LIST OF FIGURES}

Figure 1. ORNL Internally Heated High-Pressure Vessel (IHPV) .........................................

Figure 2. Temporal profile of temperature cycle in the IHPV ...............................................5

Figure 3. Method used to seal polymer against high-pressure hydrogen ..................................6

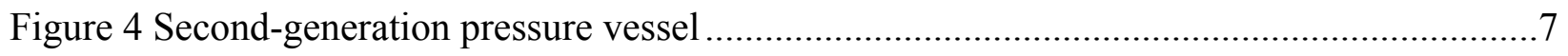

Figure 5 Second-generation temperature cycling apparatus ............................................. 7

Figure 6 Temporal profile of temperature cycle in second-generation apparatus ........................8

Figure 7 Permeation coefficients measured at 430 bar for extruded HDPE...............................10

Figure 8 Activation energy for extruded HDPE specimen during 4000 temperature cycles.........10

Figure 9 Pre-exponential scaling factor for extruded HDPE during 4000 temperature cycles .....11

Figure 10 Neutron scattering data for HDPE tank liner specimens ....................................... 12

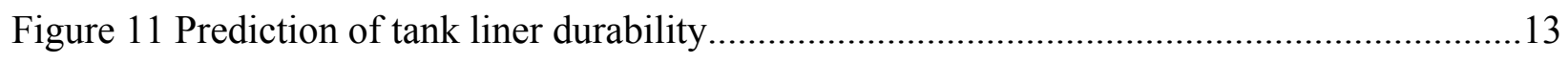

Figure 12 Temperature dependence of the hydrogen permeability for tank liner polymer specimens and a thermotropic liquid crystal polymer (TLCP) ...............................14

Figure 13 Pressure dependencies of specific permeabilities of four tank liner polymers. ............16

Figure 14 Pressure dependencies of extrusion molded HDPE, measured at several temperatures 


\section{LIST OF TABLES}

Table 1. Activation energies $E_{\mathrm{A}}$ and pre-exponential scaling factors $P_{0}$ for calculating hydrogen permeability coefficients for select polymers using Eq. 1.................................................. 15

Table 2. Dependence of specific permeability of polymers on hydrogen pressure, correlated to approximate values of their moduli...................................................................................... 16

Table 3. Dependence of specific permeability on temperature for extrusion molded HDPE....... 16 


\section{EXECUTIVE SUMMARY}

This report describes a method that was developed for the purpose of assessing the durability of thermoplastic liners used in a Type IV hydrogen storage tank during the tank's expected service life. In the method, a thermoplastic liner specimen is cycled between the maximum and minimum expected working temperatures while it is differentially pressurized with high-pressure hydrogen gas. The number of thermal cycling intervals corresponds to those expected within the tank's design lifetime. At prescribed intervals, hydrogen permeation measurements are done in situ to assess the ability of the liner specimen to maintain its hydrogen barrier properties and to model its permeability over the tank lifetime. Finally, the model is used to assess whether the steady-state leakage rate in the tank could potentially exceed the leakage specification for hydrogen fuel cell passenger vehicles.

A durability assessment was performed on a specimen of high-density polyethylene (HDPE) that is in current use as a tank liner. Hydrogen permeation measurements were performed on several additional tank liner polymers as well as novel polymers proposed for use as storage tank liners and hydrogen barrier materials.

The following technical barriers from the Fuel Cell Technologies Program MYRDD ${ }^{1}$ were addressed by the project:

- D. Durability of on-board storage systems - lifetime of at least 1500 cycles

- G. Materials of construction - vessel containment that is resistant to hydrogen permeation

- M. Lack of Tank Performance Data and Understanding of Failure Mechanisms

And the following technical targets ${ }^{1}$ for on-board hydrogen storage systems R\&D were likewise addressed:

- Operational cycle life (1/4 tank to full) -

FY 2017: 1500 cycles; Ultimate: 1500 cycles

- Environmental health \& safety -

Permeation and leakage: Meets or exceeds applicable standards

Loss of useable $\mathrm{H}_{2}$ : FY 2017: $0.05 \mathrm{~g} / \mathrm{h} / \mathrm{kg} \mathrm{H}_{2}$; Ultimate: $0.05 \mathrm{~g} / \mathrm{h} / \mathrm{kg} \mathrm{H}_{2}$

The following are the highlights and notable accomplishments of the project:

- Achieved the first rapid thermal cycling of polymers between -40 and $85^{\circ} \mathrm{C}$ at high pressures by modifying the ORNL Internally Heated Pressure Vessel diffusion/permeation measurements test stand to incorporate a low-temperature chiller with continuously circulated low-temperature refrigerant and upgrading the heater controller to provide full thermal cycling control

- Developed a technique for sealing polymer samples against high-pressure hydrogen at subzero temperatures that is a slight modification of the Bridgman method

- Completed 4000 temperature cycles on a specimen of Type IV tank liner (HDPE) while performing periodic permeation measurements on liner specimen to assess temperature-cycling induced changes in permeation coefficients

1 Hydrogen and Fuel Cells Program Multi-Year Research, Development and Demonstration Plan, Section 3.3-Hydrogen Storage 2012, accessed July 2013: http://www1.eere.energy.gov/hydrogenandfuelcells/mypp/pdfs/storage.pdf 
- Observed that permeability of temperature cycled specimen of tank liner made from extruded HDPE exhibited progressive changes in the slope and pre-exponential scaling factor of the permeation curves

- Observed small systematic changes in activation energy $E_{A}$ and constant $P_{0}$ in the extruded HDPE specimen during temperature cycling

- Characterized porosity of liner specimen using neutron scattering and electron microscopy (SANS, USANS, SEM/BSE) and observed significant structural changes induced by temperature cycling or hydrogen exposure or both

- Observed that repetitive temperature cycling decreases $\mathrm{H}_{2}$ permeability in specimens of extruded HDPE by increasing the size of the crystalline regions in the polymer

- Using permeation coefficient data, modeled the lifecycle permeability of a liner in a 350-bar tank and predicted that it can be expected to maintain an $\mathrm{H}_{2}$ leak rate that meets applicable leakage standards throughout its lifecycle

- Designed and assembled improved temperature-cycling apparatus that provides temperature cycling between $-40^{\circ} \mathrm{C}$ and $85^{\circ} \mathrm{C}$ with shorter temperature cycles of $\sim 20$ minutes ( $40 \%$ shorter than cycling time in original apparatus), a maximum differential hydrogen pressure across specimen of $\sim 900$ bar (13,000 psia), while using less hydrogen and substantially less electrical power 


\section{INTRODUCTION}

Vehicles powered by hydrogen fuel cells require on-board storage of hydrogen. Presently this storage need is being met through the use of composite-overwrapped pressure vessels (COPVs) that are capable of storing gaseous hydrogen at pressures as high as $70 \mathrm{MPa}$. These COPV storage tanks are required to meet or exceed applicable safety and performance requirements, including a minimum of 500 fill cycles during the lifecycle of the COPV.

Type IV tanks utilize a polymeric liner as a permeation barrier for the stored hydrogen, a carbon-fiber epoxy matrix reinforcement overwrap on the liner that contains the pressure load, and a fiberglass shell that protects the overwrap. The liner is typically a thermoplastic such as high-density polyethylene (HDPE) or polyamide (PA) formed as a cylinder with hemispherical ends. The liner is produced by extrusion, rotomolding or blow molding, or some combination thereof through the use a of plastic jointment technique.

The tank liners are stressed during filling operations and by the cyclical pressure excursions that occur as environmental temperatures reach extreme values. The cumulative effects of repeated stress could reduce the durability of the liner. Ultra-high environmental temperatures can promote large hydrogen permeation rates and hydrogen saturation in the liner material. Ultra-low environmental temperatures can possibly induce microcracking. In addition, increasing the pressure of gas in such a tank during filling necessarily raises the temperature of the gas and the -pressure-load-bearing carbon-fiber reinforced shell. Over the course of hundreds of fill cycles during the lifetime of the tank, these environmental stresses could affect the permeability characteristics of the liner and failure modes for the liner's performance-based on the interaction of high pressure and extreme temperature cycling-might be introduced. Hydrogen leakage through a liner microcracked by extreme temperature cycling could accelerate under sustained high temperature and pressure, or hydrogen saturation of the reinforcement layers external to the liner could put backpressure on the liner as the tank pressure decreases during vehicle operation, thereby causing the liner to separate from the reinforcement layers. Minimum temperatures during winter months in northern states may reach well below $0^{\circ} \mathrm{C}$, tank precooling before filling could reach $-40^{\circ} \mathrm{C}$, and maximum temperatures after filling during summer months may reach $85^{\circ} \mathrm{C}$. Thus, the purpose of this project is to cycle typical tank liner materials between these temperature extremes to determine whether such a degradation in properties occurs, and, if so, its extent. 


\section{APPROACH}

To address the issue of tank liner durability ORNL has performed hydrogen permeation verification measurements on storage tank liner materials using specially designed experimental facilities that provide rapid thermal cycling of polymeric liner specimens between -40 and $85^{\circ} \mathrm{C}$ at a rate of about two to three temperature cycles per hour. This temperature cycling is done while the liner specimens are differentially pressurized to 430 or 860 bar $(6,250$ or $12,500 \mathrm{psi})$. The newest of the two experimental apparatuses has the potential to cycle at differential pressures as high as $\sim 1000$ bar and temperatures near the polymer softening points.

We developed test protocols for durability test cycling measurements of high-pressure polymeric tank liners using relevant portions of SAE J2579. ${ }^{2}$ The $\mathrm{J} 2579$ protocol for compressed hydrogen storage systems prescribes long-term thermal cycling at high pressures of hydrogen. The J2579 durability requirement for tank liners is 5500 thermal cycles over the range -40 to $85^{\circ} \mathrm{C}$ at hydrogen pressurizations of $43 \mathrm{Mpa}(6,250 \mathrm{psia})$ and $86 \mathrm{Mpa}(12,500 \mathrm{psia})$.

The initial hydrogen permeation verification measurements for storage tank liner materials were carried out using ORNL's internally heated high-pressure permeation test vessel (IHPV) shown in Figure 1. The IHPV can be used for semi-automatic hydrogen diffusion and permeation measurements at temperatures over the range 10 to $1000^{\circ} \mathrm{C}$ and at pressures as large as $276 \mathrm{Mpa}(40,000 \mathrm{psi})$. (This apparatus was used earlier in related HFCT hydrogen delivery program work to determine real-time hydrogen permeation in low-carbon steels and polymer materials.) Materials characteristics such as the temperature- and pressure-dependent hydrogen solubilities, diffusion coefficients and permeation coefficients are extracted from measurements of real-time hydrogen flux through steels and polymers.

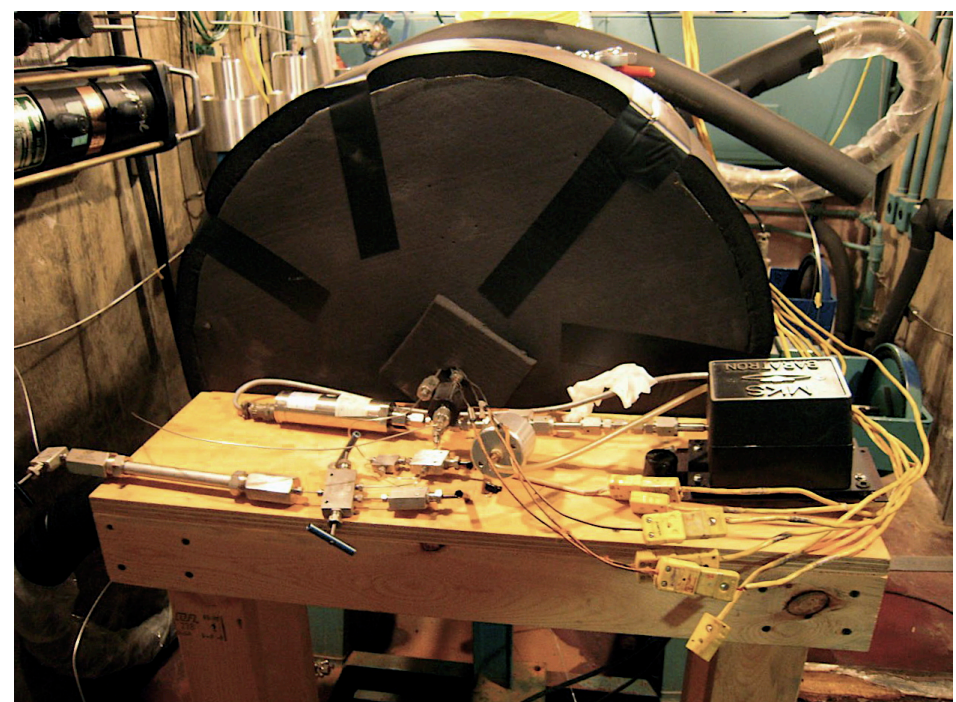

Figure 1. Specimen loading end of ORNL Internally Heated High-Pressure Vessel

\footnotetext{
2 SAE J2579, “Technical Information Report for Fuel Cell and Other Hydrogen Vehicles (January 2009)," Fuel Cell Standards Committee, SAE International.
} 
(IHPV), which was modified to provide rapid temperature cycling of differentially pressurized polymer specimens.

Testing tank liner specimens at 43 and $86 \mathrm{MPa}$, with rapid cycling between -40 and $125^{\circ} \mathrm{C}$, required an automated temperature control strategy. To replicate the rapid temperature rise in the tank liner during fill cycles (approximately $100^{\circ} \mathrm{C}$ temperature rise in 3 minutes), we decoupled the cooling and heating control systems in the IHPV. A low-temperature chiller with low-temperature coolant circulated to and from a sealed reservoir to cool the IHPV's exterior containment vessel to approximately $-50^{\circ} \mathrm{C}$. A resistive heater situated in the permeation cell was used to ramp the specimen temperature from $-40^{\circ} \mathrm{C}$ to $85^{\circ} \mathrm{C}$. A PID heater controller directed the thermal cycling of the polymer specimen in the cell by applying and removing power to the heater. Process control software that was developed for the temperature controlled permeation measurements in steels and polymers was modified to provide automated, unattended operation access so the tests could be remotely monitored and controlled via the ORNL intranet.

Figure 2 shows a typical temporal profile for a temperature cycle in the modified IHPV. In this case the cycle was 33.3 minutes long, with a 5.7-minute-long heating interval followed by a 27.6-minute-long cooling interval. The heating rate was selected to provide a $20^{\circ} \mathrm{C}$ per minute temperature rise similar to what might occur in a storage tank liner during filling. The cooling rate is simply governed by the thermal mass and heat transfer of the specimen holder.

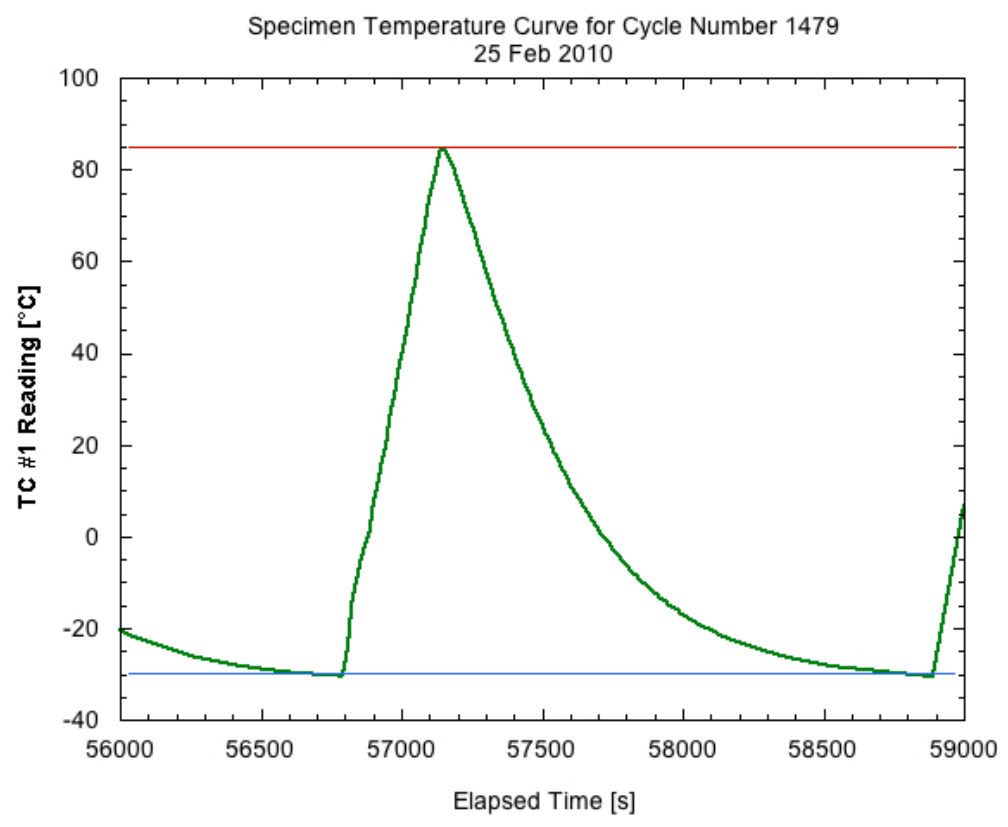

Figure 2. Temporal profile of temperature cycle in the IHPV.

The polymer specimens were prepared from liners provided by manufacturers of type IV hydrogen storage tanks. The tank liners provided were too thick to use for permeation measurements and they were often curvilinear in shape, so we prepared flat coupons by lathe-turning small sections of the liners to thicknesses of 0.5-1 mm. The turning was done on the exterior (low pressure) side of the liner. The thinned liner was then punched into a $1.0-\mathrm{cm}$ diameter disc for testing in the IHPV. The turned sided of 
the punched disc was wet sanded with a succession of progressively finer grits through ISO P1200. The specimen disc is oriented in the pressure vessel so the liner interior (pristine surface) was exposed to the high-pressure hydrogen. In the IHPV a $0.9-\mathrm{cm}$ diameter circular area was directly exposed to highpressure $\mathrm{H}_{2}$, and this is the area over which the gas transfer rate was determined.

To seal the thin polymer sample against high-pressure hydrogen at subzero temperatures we used an improvised Bridgman seal design (see Figure 3). In the illustration the high-pressure hydrogen was incident against the upper surface of the sample and the subatmospheric pressure side was the lower surface. At subzero temperatures the polymer eventually shrinks due to compression and the sealing surface (1-mm wide annular ring) loses solid mechanical contact with the conical copper sealing ring. Through trial and error we found that it is possible to mitigate this contact loss due to compression by pre-forming the polymer to have a conical shape similar to the sealing ring. This was done by placing the polymer specimen against a conically shaped steel specimen and tightening the sandwiched polymer and steel specimens in the specimen holder to force the polymer specimen to acquire a conical contour at its edges without deforming the specimen thickness. The sandwiched specimens were then removed and replaced by the polymer specimen alone. However, even with this improved design for sealing, we found it was occasionally necessary to remove the specimen from the

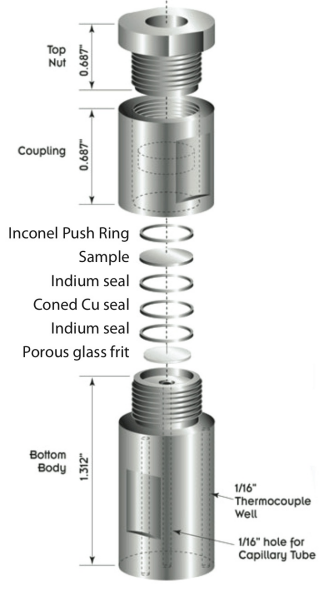

Figure 3. Illustration of method used to seal polymer sample against high-pressure hydrogen at subzero temperatures. IHPV to retighten the top nut, which loosened a fraction of a turn during prolonged temperature cycling.

In the second project year we designed a new high-pressure temperature cycling apparatus that we hoped would be immune to the many difficulties we faced while temperature cycling specimens in the IHPV. The primary limitation of the modified IHPV was the long cooling interval attributable to the very slow heat transfer conditions imposed by the large thermal mass of the IHPV. A second limitation was the small surface area of the 1-mm-diameter specimens. The hydrogen transfer rate was measured over the 0.9-cm-diameter circular area in contact with the high-pressure hydrogen. The increased area of a largerdiameter specimen would provide faster and more accurate permeation measurements.

To this end we designed the second-generation pressure vessel to have a fraction of the mass of the IHPV. The closed vessel is shown in Figure 4. Its smaller size and weight (4 kg) enabled us to cool it by immersing it in the reservoir of a low-temperature recirculating bath. The pressure vessel is comprised of two type 316 stainless steel flanges that are bolted together in a configuration designed to withstand working pressures up to 860 bar. The polymer specimen being evaluated is sealed by compression in an annular ring $\left(10 \mathrm{~cm}^{2}\right.$ sealing area) between the two flanges. The vessel is immersed in a chilled bath (reservoir) of ethylene glycol and distilled water at a temperature that varies from -30 to $-50^{\circ} \mathrm{C}$ during the temperature cycling. The reservoir is the low-temperature heat sink for the vessel during the cooling interval and its temperature rises as it absorbs heat from the vessel following the heating interval. The vessel is heated with six 300 watt ( $1800 \mathrm{~W}$ total) immersible cartridge heaters spaced at $60^{\circ}$ in the vessel just outside the specimen edge. The entire temperature cycling/permeation measurement apparatus is 
shown in Figure 5. It occupies less than a tenth of the floor space of the IHPV (not including the floor space of the control room). The specimen is continuously differentially pressurized during temperature cycling, with the high-pressure hydrogen on one side of the specimen and a sub-atmospheric pressure maintained on other side with a dry vacuum pump. The permeation measurements are performed with the specimen in the pressure vessel by measuring the rate of the pressure rise rate in the fixed downstream volume and calculating a gas transfer rate from the pressure rise rate.

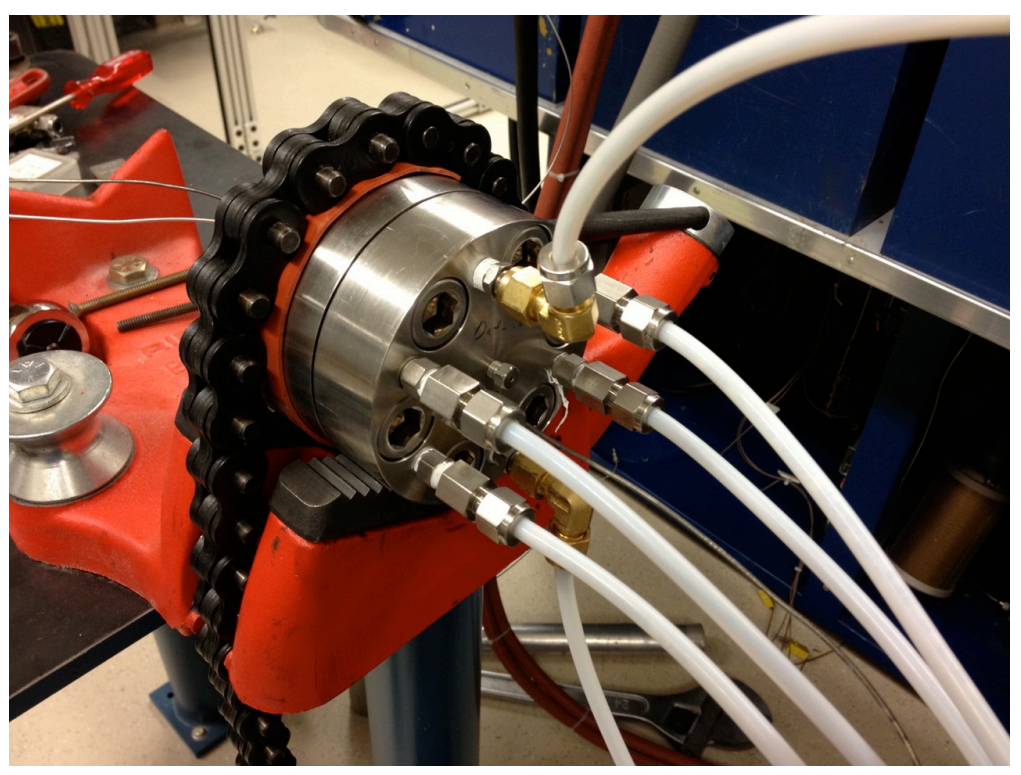

Figure 4. Assembled pressure vessel showing water-tight electrical connections to cartridge heaters and bolt configuration.

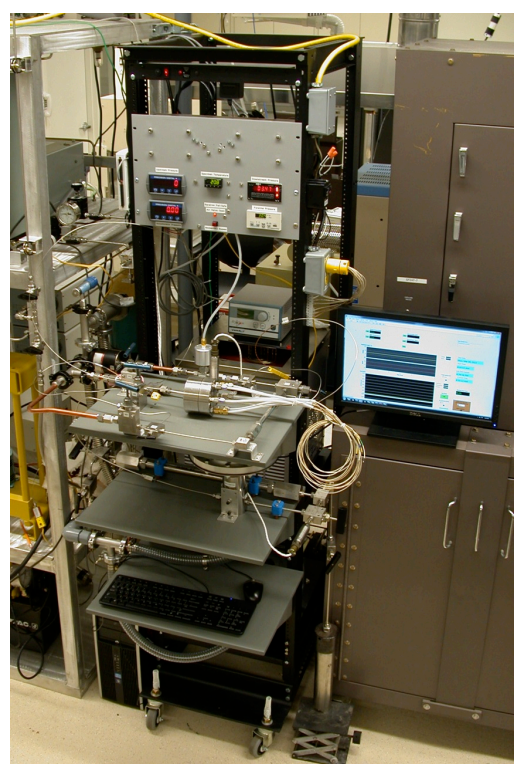

Figure 5. Second-generation temperature cycling apparatus.

The polymer specimens in the second-generation apparatus are discs $5.7 \mathrm{~cm}$ in diameter and approximately 1-mm thick. The gas transfer area (the area exposed to high pressure hydrogen on one side and below atmospheric pressure on the other) is $4.5 \mathrm{~cm}$ in diameter. The specimens are prepared in the same manner as those for the IHPV-by lathe turning and wet sanding on low-pressure side. The liner interior (pristine surface) is the side exposed to the high-pressure $\mathrm{H}_{2}$.

Figure 6 shows a temporal profile of the temperature-cycle in the second-generation apparatus. The heating rate is $20^{\circ} \mathrm{C} / \mathrm{min}$ and the cooling rate averages about $-5^{\circ} \mathrm{C} / \mathrm{min}$. The cooling interval is longer than expected but is a few minutes shorter than that in the IHPV. Our design for the second-generation apparatus were based on heat transfer from the hot vessel into a bath with a temperature between $-40^{\circ} \mathrm{C}$ and $-50^{\circ} \mathrm{C}$. We later discovered that the cooling power of the low temperature bath was unexpectedly low at temperatures below $-30^{\circ} \mathrm{C}$ and it was difficult to circulate the extremely viscous ethylene glycol-water mixture around the vessel. The bath was therefore unable to expeditiously absorb the heat added during the heating interval. We tried several approaches for further reducing the cooling interval. The only successful approach was to add a secondary ultra-low temperature bath to circulate coolant through a copper coil immersed inside the vessel bath to draw out the excess added heat. The secondary bath has extremely good cooling power at $-50^{\circ} \mathrm{C}$. 


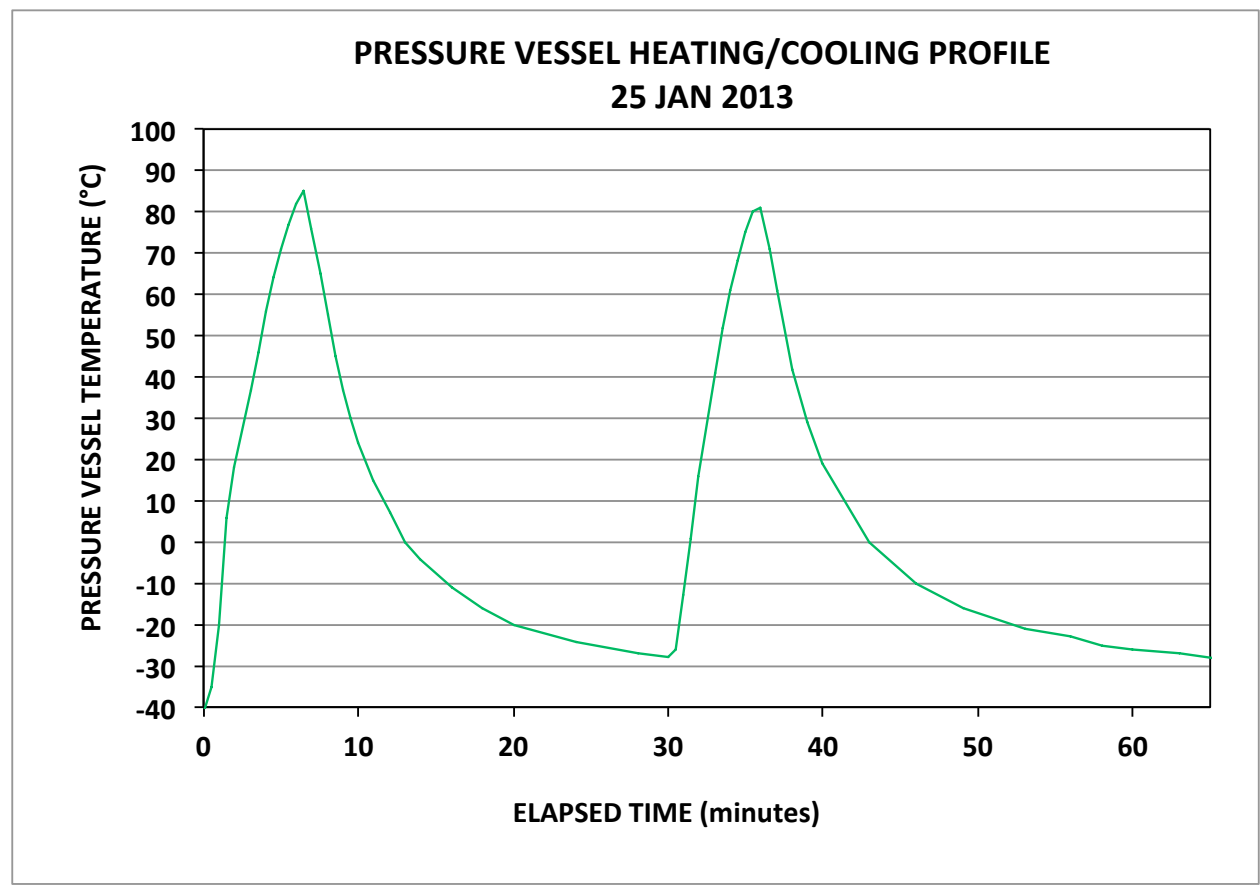

Figure 6. Temporal profile of temperature cycle in second-generation apparatus. 


\section{RESULTS}

The first polymer evaluated in the IHPV was a specimen of extruded high-density polyethylene (HDPE). The differential hydrogen pressure was 430 bar. The permeation coefficients were measured at the prescribed intervals during the temperature cycling at four temperatures $\left(-40,-10,30\right.$ and $\left.85^{\circ} \mathrm{C}\right)$, when practicable. The first six sets of permeation measurements were done following $250,500,750,1000$, 1250 and 1500 cycles. The remaining measurements were done at 500 cycle intervals until we observed a statistically significant trend in the Arrhenius relationship or until 5500 temperature cycles had been reached.

The permeation coefficients $P$ have the temperature dependence of an activated process, i.e., $P=P_{0} \exp \left(-E_{\mathrm{A}} / \mathrm{k} T\right)$, where the pre-exponential scaling factor $P_{0}$ and the activation energy $E_{\mathrm{A}}$ are presumed to be independent of temperature.

We concluded the temperature cycling following 4000 permeation measurements. Plots of the Arrhenius curves $(\log P$ versus $1 / T)$ are shown in Figure 7 . Lines have been drawn through measurements at 0 , 1000, 2000, 3000 and 4000 cycles to illustrate the systematic changes in $E_{\mathrm{A}}$ and $P_{0}$. The decreasing slope and shift in scaling indicates that physical changes were occurring in the polymer during cycling. We did

not observe a statistically significant departure from the Arrhenius relationship, which would indicate that microcracking or changes in glass transition temperature had occurred in the polymer. Figures 8 and 9 illustrate the changes in $E_{\mathrm{A}}$ and $P_{0}$, respectively. $E_{\mathrm{A}}$ and $P_{0}$ each decreased as the specimen was subjected to repeated temperature cycles. The $-2.21 \mathrm{~J} /$ mole slope for $E_{\mathrm{A}}$ versus number of cycles was approximately five standard deviations from a slope of zero, and the $4.6 \times 10^{-8} \mathrm{~mol} \mathrm{H}_{2} / \mathrm{cm} \cdot \mathrm{s} \cdot \mathrm{bar}$ slope for $P_{0}$ versus number of cycles was approximately 4 standard deviations from a slope of zero. 


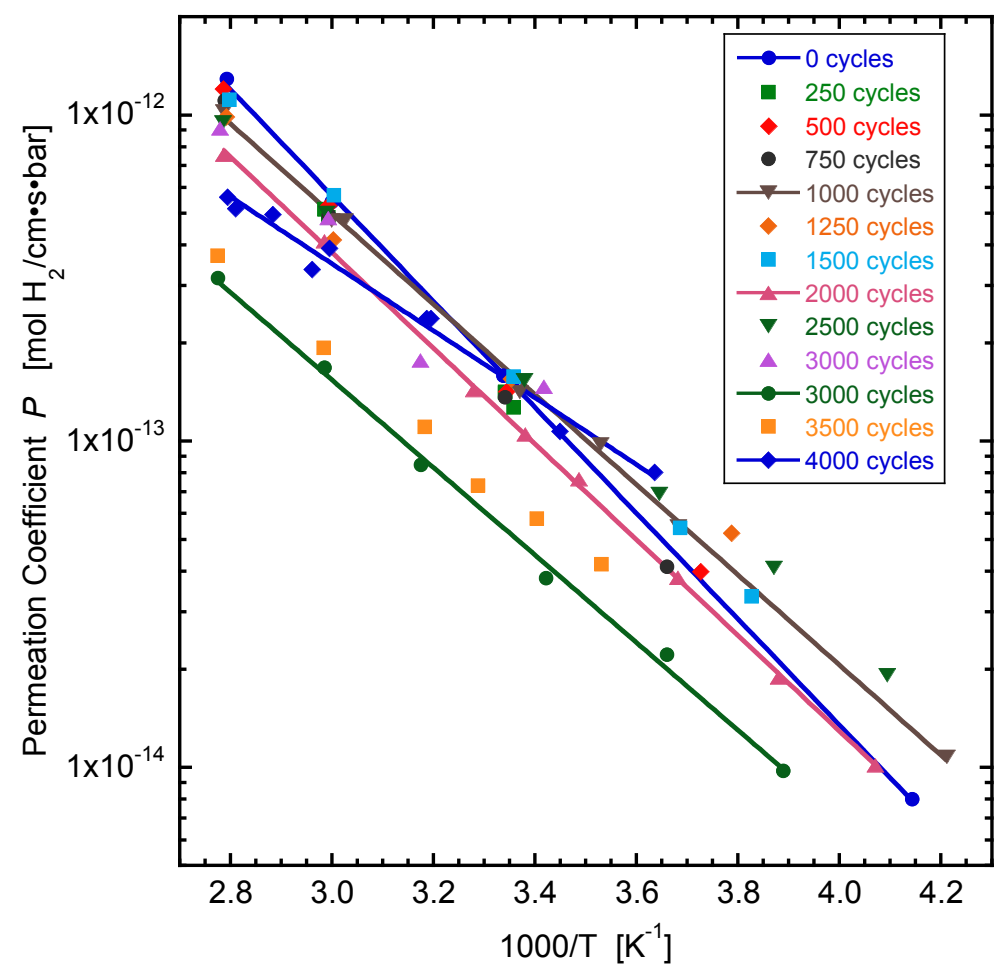

Figure 7. Permeation coefficients $P$ for hydrogen, measured at 430 bar, in specimen of extruded HDPE.

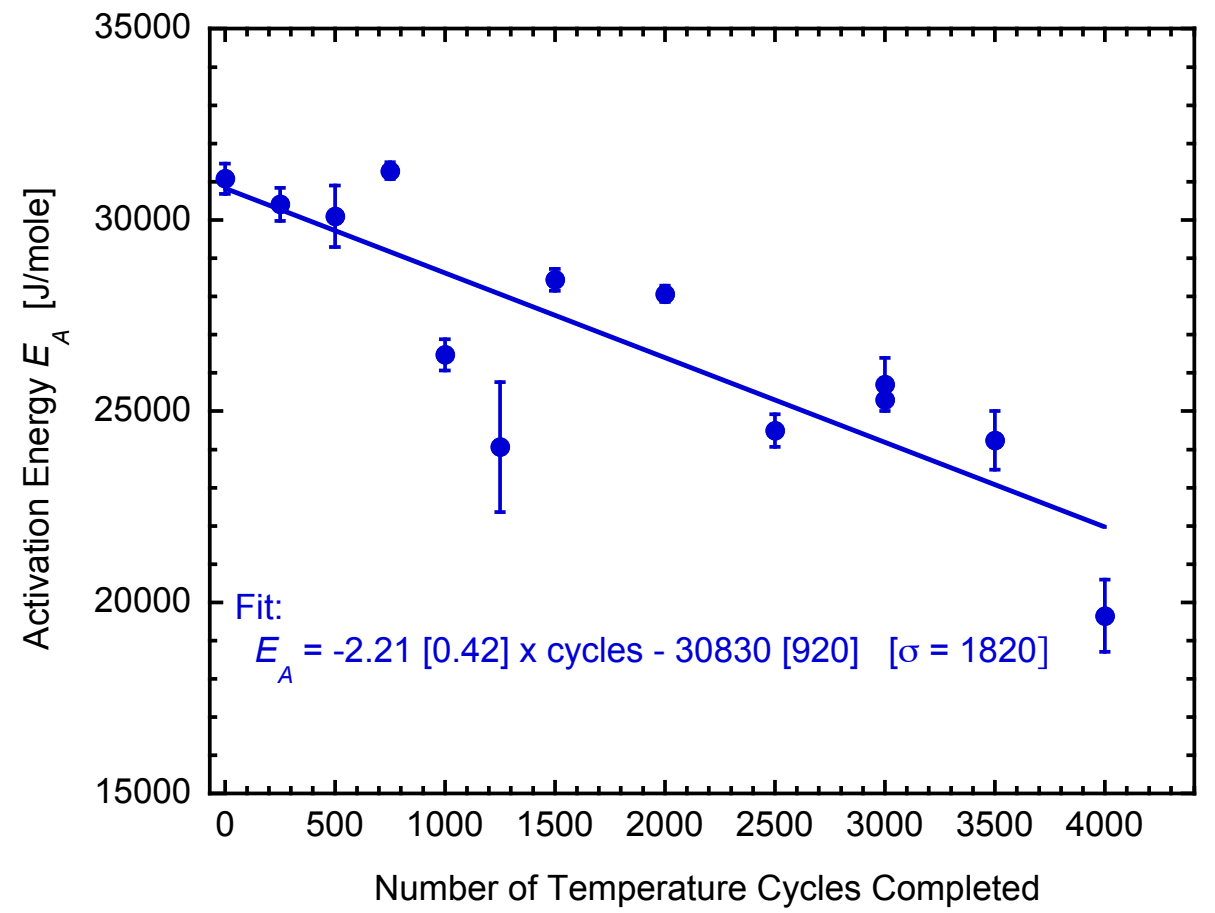

Figure 8. Activation energy $E_{\mathrm{A}}$ of the extruded HDPE specimen decreased during 4000 temperature cycles, indicating that changes in polymer occurred during temperature cycling. 


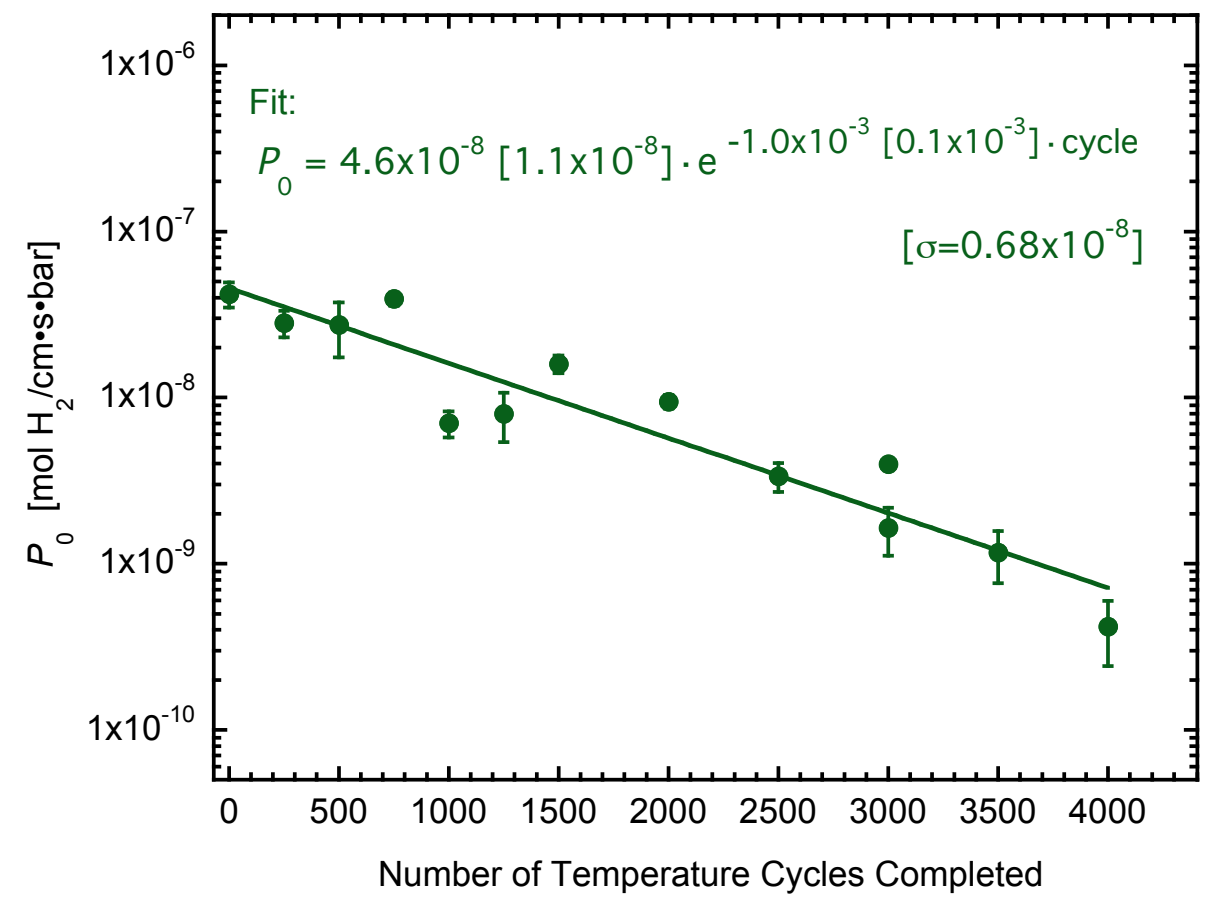

Figure 9. Pre-exponential scaling factor $P_{0}$ also decreased during 4000 temperature cycles, further evidencing small changes in polymer microstructure.

Following completion of the temperature cycling we used neutron scattering analysis (SANS and USANS) to look for structural changes on the order $1 \mathrm{~nm}$ to $30 \mu \mathrm{m}$ in the polymer. We analyzed four HDPE tank liner specimens: 1, before temperature cycling; 2, after a few temperature cycles; 3, after 600 cycles; and 4, after 4000 cycles. The scattering data for the before-cycling and after-4000 cycles specimens is shown in Figure 10. The scattering data was analyzed as follows ${ }^{3}$ : the low-q section was fit using a Guinier-Porod model, the central section was fit using a flexible cylinder with a polydispersed radius model (designed for treatment of polymers, see Reference 3), and the high-q section was fit to a polydispersed (Gaussian) sphere model. In the low-q section, the fit changes slope from -4 (Porod region) to -2 (Guinier region corresponding to plates or laminae). The transition from Porod to Guinier occurs with increasing number of temperature cycles. The presence of low-q scattering in the (U)SANS data indicates the presence of large-scale $(>30 \mu \mathrm{m})$ scattering features that change significantly with longterm exposure to hydrogen or increasing number of temperature cycles or both. Similarly, the presence of high-q scattering appears only after temperature cycling. We interpret this analysis as evidence that the temperature cycling induced significant changes in the size of the pores.

\footnotetext{
${ }^{3}$ B. Hammouda, The SANS Toolbox, NIST Center for Neutron Research, available at http://tinyurl.com/SANStoolbox
} 

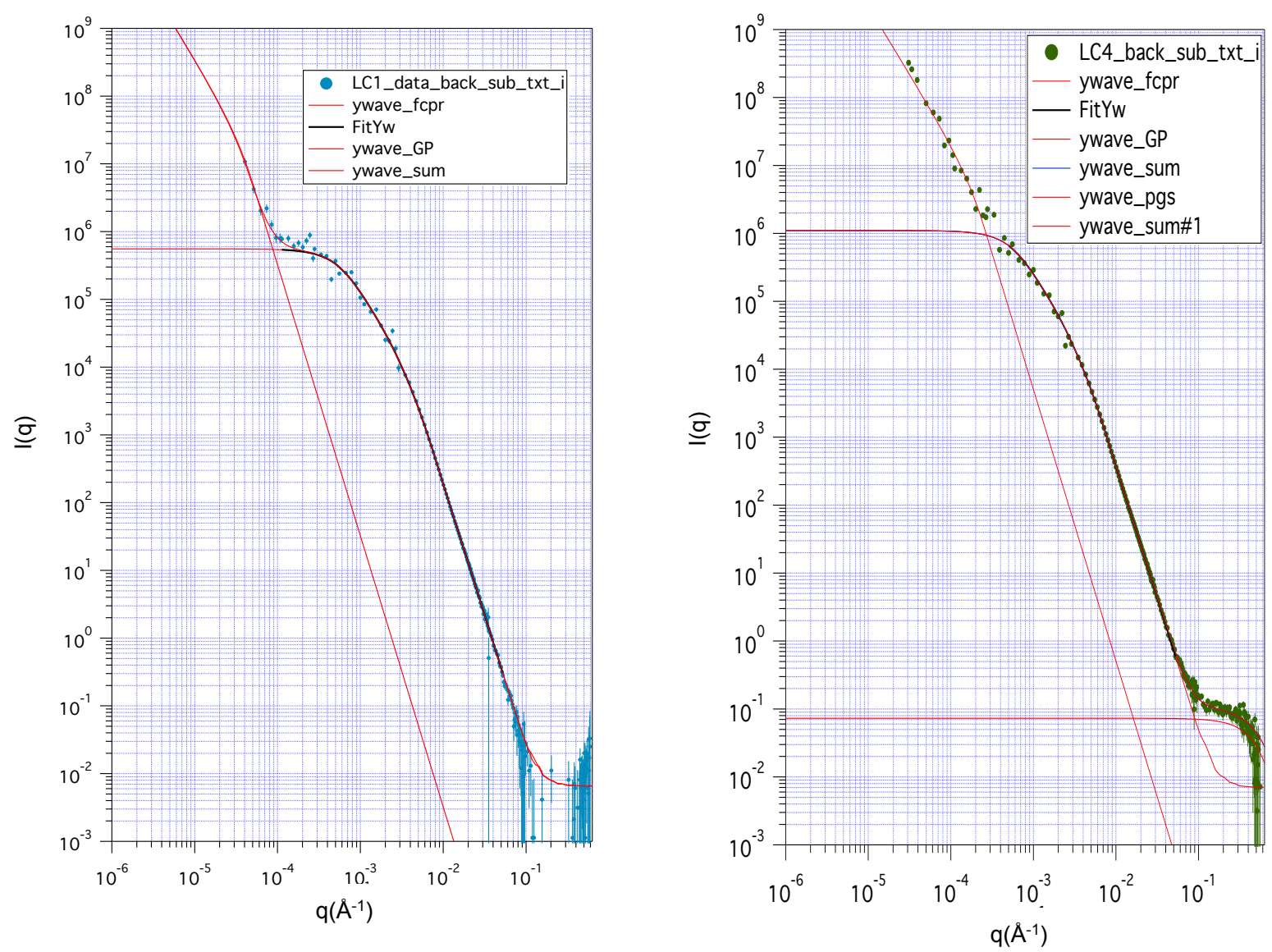

Figure 10. Neutron scattering data for HDPE tank liner specimens, before temperature cycling (left) and after 4000 temperature cycles (right).

To estimate the potential effect of temperature cycling on a complete tank liner, we used the values of $P_{0}$ and $E_{\mathrm{A}}$ obtained from the permeation measurements to model the behavior of the permeation coefficients $P$ as a function of $T$ and the number of cycles. This modeling shows that at all temperatures the values of the hydrogen permeation coefficients decrease with cycle count, thus implying that the hydrogen leak rate of the tank liner should decrease with the number of temperature cycles.

To obtain a quantitative prediction of the leak rate for an actual tank liner, we used the dimensional specifications for a hydrogen storage tank rated for 700 bar service with a volumetric capacity of 118 liters ( $4.8 \mathrm{~kg} \mathrm{H} 2$ capacity). The HDPE tank liner is cylindrical with approximately hemispherical end caps, and the liner wall thickness is about $7 \mathrm{~mm}$. We used the values of P0 and EA obtained from measurements during the temperature cycling to model the behavior of the permeation coefficients $\mathrm{P}$ as a function of temperature and the number of cycles. This modeling shows that at all temperatures the values of the hydrogen permeation coefficients decrease with cycle count. Thus the hydrogen leak rate of the tank liner should decrease with the number of temperature cycles. In this analysis the tank leak rate remains below $75 \mathrm{Ncc} / \mathrm{min}$ (normal cubic centimeters per minute) at all temperatures for the duration of 4000 temperature cycles. Furthermore, for all liner temperatures less than about $60^{\circ} \mathrm{C}$, the loss of useable hydrogen remains below $0.05 \mathrm{~g} / \mathrm{h} / \mathrm{kg} \mathrm{H} 2$ for a fully filled tank. 


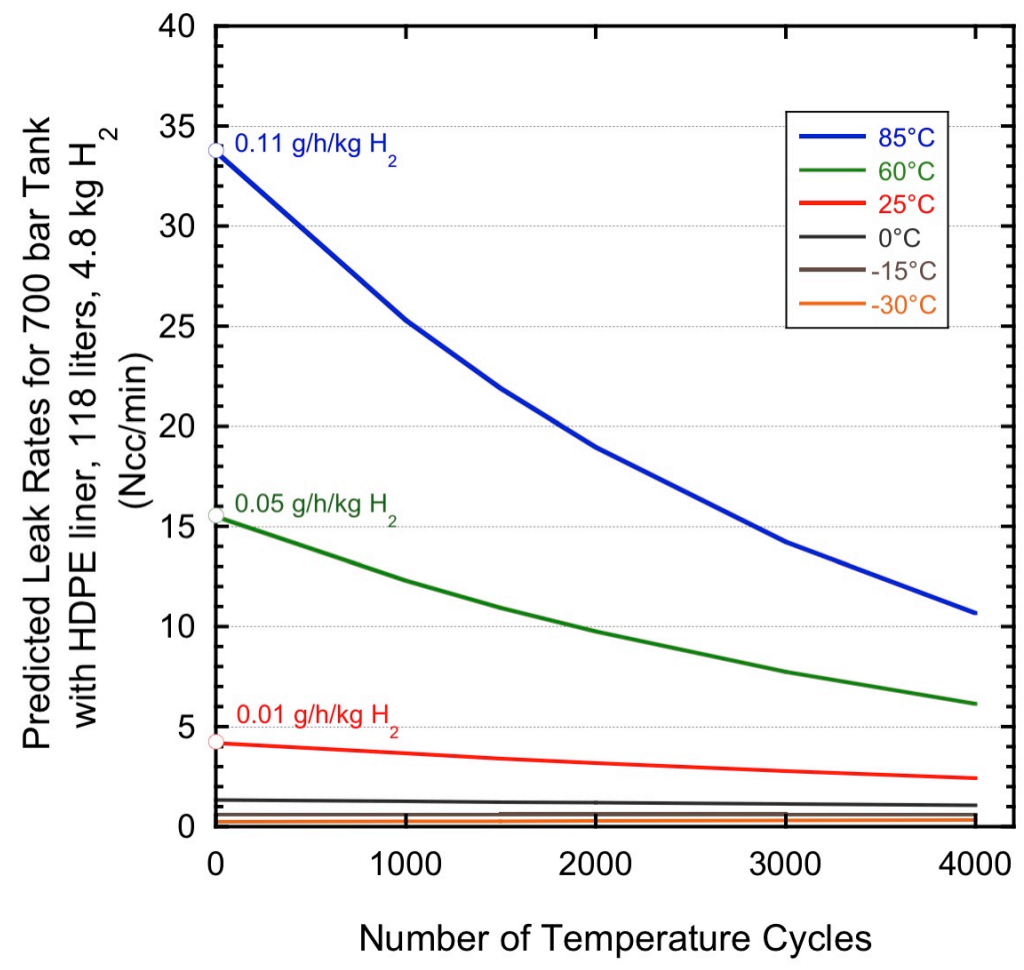

Figure 11. Prediction of tank liner durability (changes in hydrogen leak rates) using modeled permeability coefficients $P$ to calculate leak rates in an HDPE-lined cylindrical tank with hemispherical end caps. A family of curves corresponding to predicted leak rates at varying temperatures are plotted as a function of the number of temperature cycles the tank is expected to experience due to fill operations and variations in ambient temperature.

In addition to the temperature cycling measurements we conducted an extensive series of hydrogen diffusion and permeation measurements on tank liner polymers to characterize the relative hydrogenbarrier capabilities of the polymers and the pressure-dependence of the permeability coefficients. Presentation of the entirety of the results of these measurements will be published in the near future in the archival literature. In this report we present highlights of the permeability measurements that we expect will be of use to researchers and technologists who are investigating the use of polymeric materials in hydrogen storage and delivery systems.

Figure 12 shows the temperature dependence of the hydrogen permeability coefficients for four polymers being evaluated for durability in the temperature cycling experiments, as well as the coefficients for a thermotropic liquid crystal polymer (TLCP). TLCPs have been proposed for use as a hydrogen barrier material due to their lower permeabilities. The TLCP evaluated was compression-molded DuPont HX 3000. The other polymers were proprietary formulations provided by storage tank manufacturers. The measurements shown were made at temperatures ranging from -30 to $85^{\circ} \mathrm{C}$ at a differential pressurization of approximately 135 bar (2000 psia) with the exception of the rotationally molded (rotomolded) HDPE, which was done at 345 bar (5000 psia). Measurements of the permeability coefficient values were 
extremely reproducible for HDPE, PA-6 and PET polymers. Measurements of the TLCP permeability coefficients were much less reproducible, and reliable measurements could not be made at temperatures below $10^{\circ} \mathrm{C}$. It was difficult to prepare specimens from the TLCP due to its brittleness and tendency to become friable at cut edges, and TLCP specimens exhibited a substantial amount of creep and deformation following pressurization at temperatures substantially above room temperature.

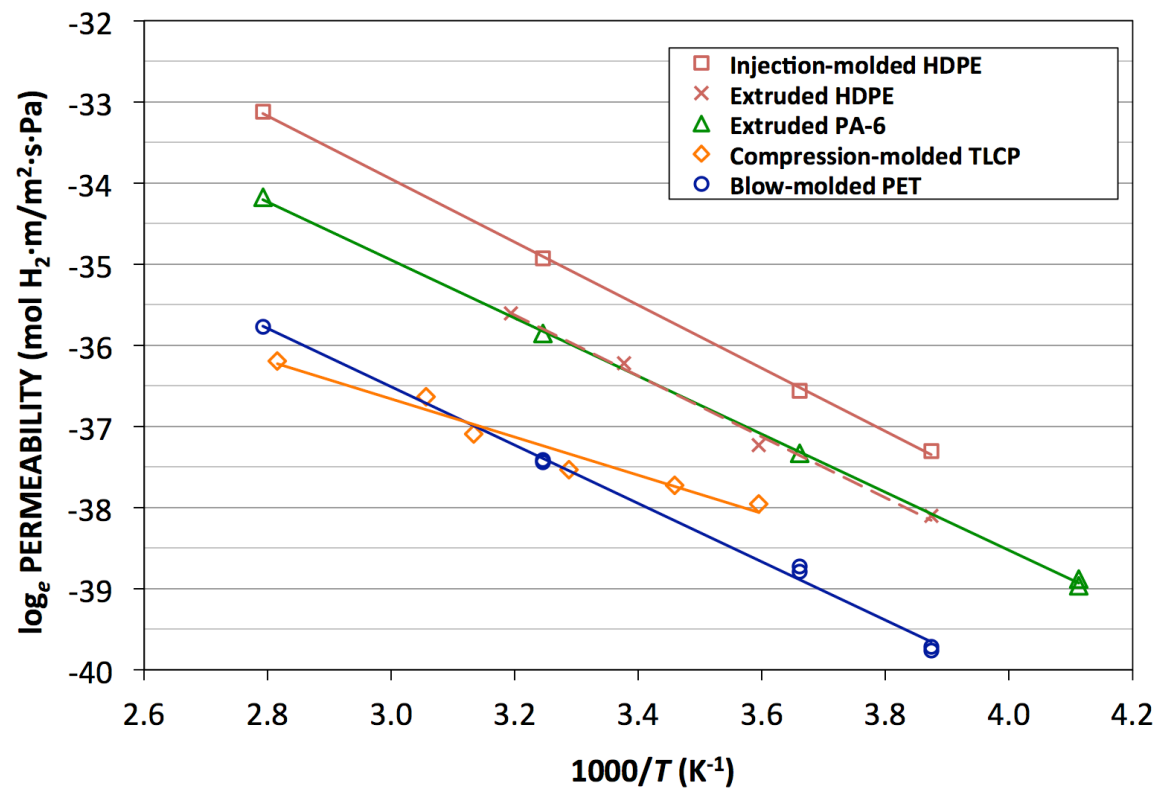

Figure 12. Temperature dependence of the hydrogen permeability for four tank liner polymer specimens plus a specimen of a thermotropic liquid crystal polymer (TLCP). All measurements were made using a differential hydrogen pressure of $134 \mathrm{bar}(13,400 \mathrm{kPa})$ with the exception of the rotomolded HDPE, which was measured at 345 bar $(34,500 \mathrm{kPa})$.

There were no statistically significant differences between the permeabilities of the HDPE produced by extrusion molding, rotational molding, and injection molding manufacturing processes. The permeability of PET was about an order of magnitude less than that of HDPE. The permeability of TLCP is comparable to that of blow-molded PET.

The temperature dependence of the permeability coefficients for a particular polymer at a specified hydrogen pressure can be modeled very accurately by the Arrhenius equation for an activated process, i.e.,

$$
P=P_{0} e^{-E_{A} / R T} \quad \text { Eq. } 1
$$

where $E_{\mathrm{A}}$ is the activation energy for permeation in $\mathrm{J} / \mathrm{mole}, R$ is the gas constant, $T$ is the temperature in Kelvin, and $P_{0}$ is a pre-exponential scaling factor in $\mathrm{mol} \mathrm{H}_{2} \cdot \mathrm{m} / \mathrm{m}^{2} \cdot \mathrm{s}$. Table 1 lists the $E_{\mathrm{A}}$ and $P_{0}$ coefficients determined by a least-squares fit to the permeation measurements. The TLCP has activation energy and pre-exponential factor that are unusually low and high, respectively, when compared to the other polymers. 
Table 1. Activation energies $E_{\mathrm{A}}$ and pre-exponential scaling factors $P_{0}$ for calculating hydrogen permeability coefficients for select polymers using Eq. 1.

\begin{tabular}{|c|c|c|c|}
\hline Polymer & $\begin{array}{c}\text { Pressure } \\
\text { bar }\end{array}$ & $\begin{array}{c}E_{\mathrm{A}} \\
\mathrm{kJ} / \mathrm{mol} \mathrm{H}_{2} \\
\end{array}$ & $\begin{array}{c}P_{0} \\
\operatorname{mol~H_{2}} \cdot \mathbf{m} / \mathbf{m}^{2} \cdot \mathrm{s} \\
\end{array}$ \\
\hline Injection-molded HDPE & 134 & $32.3[0.5]$ & $2.08 \times 10^{-10}$ \\
\hline Extrusion-molded HDPE & 104 & $31.2[1.7]$ & $5.51 \times 10^{-11}$ \\
\hline Rotomolded HDPE & 345 & $32.1[0.8]$ & $2.58 \times 10^{-10}$ \\
\hline Extrusion-molded PA-6 & 137 & $30.0[0.2]$ & $3.38 \times 10^{-11}$ \\
\hline Compression-molded TLCP & 136 & $19.5[2.0]$ & $7.09 \times 10^{-13}$ \\
\hline Blow-molded PET & 137 & $29.9[0.9]$ & $6.71 \times 10^{-12}$ \\
\hline
\end{tabular}

The standard error for $E_{\mathrm{A}}$ is shown in square brackets.

Hydrogen transport in polymers differs from that in metals in one important aspect: it is not necessary for the hydrogen molecule to dissociate prior to dissolution in polymers. Sieverts' Law, which predicts that the solubility of hydrogen gas in metals will be proportional to the square root of the partial pressure of the gas in thermodynamic equilibrium, is not applicable to polymers. Thus the concentration of hydrogen dissolved in a polymer should be linearly proportional to applied pressure rather than proportional to the square root of the applied pressure. The permeability is directly proportional to the solubility, and thus the permeability of hydrogen in polymers should likewise be linearly proportional to the pressure.

Figure 13 shows the dependence of the specific permeabilities $P_{\text {sp }}$ of several tank liner polymers on hydrogen pressure (mechanical pressure, which translates into an applied force to the polymer). We observed slight deviations from a linear dependence of $P_{\mathrm{sp}}$ on pressures in the range 100 to $14,000 \mathrm{kPa}$. The amount of deviation roughly follows the Young's modulus of the polymer-the larger the modulus, the more compressible the polymer, and the less linear the dependence of $P_{\mathrm{sp}}$ on pressure. This deviation from linear pressure dependence is evidenced by the data shown in Table 2. The slope of the $P_{\mathrm{sp}}$ versus pressure curves increases as the modulus $E$ increases. It follows that the polymer is being elastically compressed by the hydrogen pressure, and the compression reduces the free volume in the polymer. Polymers with larger moduli are more resistant to compression and therefore have $P_{\text {sp }}$ values that are more linear with pressure. 


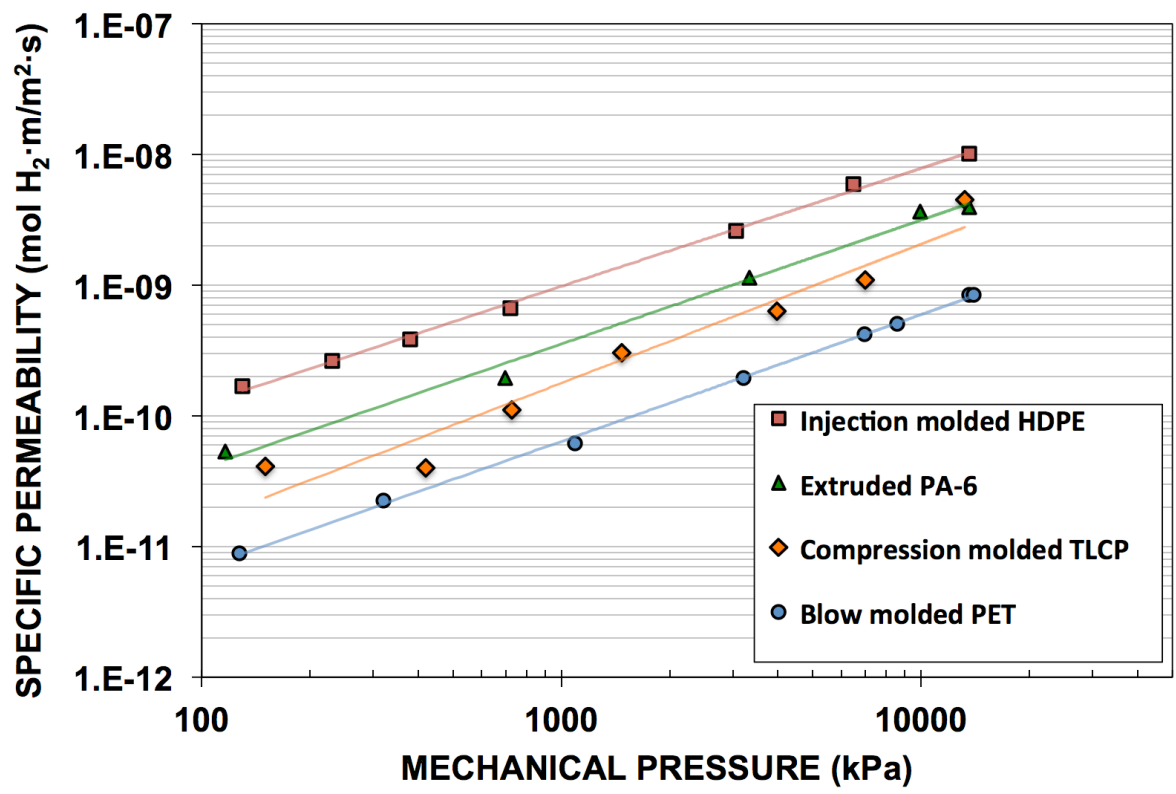

Figure 13. Pressure dependencies of the specific permeabilities of four tank liner polymers.

Table 2. Dependence of specific permeability of polymers on hydrogen pressure, correlated to approximate values of their moduli.

\begin{tabular}{lcc}
\hline \hline Polymer & $\begin{array}{c}\text { Pressure dependence of } \boldsymbol{P}_{\mathbf{s p}} \\
\left(\mathbf{m o l ~ H} \mathbf{~}_{\mathbf{2}} \cdot \mathbf{m} / \mathbf{m}^{\mathbf{2}} \cdot \mathbf{s} / \mathbf{k P a}\right)\end{array}$ & $\begin{array}{c}\boldsymbol{E} \\
\mathbf{M P a})\end{array}$ \\
\hline Injection molded HDPE & $0.89[0.02]$ & 1000 \\
Extrusion molded PA-6 & $0.95[0.05]$ & 2400 \\
Blow molded PET & $0.95[0.01]$ & 3100 \\
Compression molded TLCP & $1.06[0.11]$ & $>8000$ \\
\hline \hline
\end{tabular}

The standard error for each dependency is shown in square brackets.

This compressibility effect is likewise evident in the case where the pressure dependence of $P_{\mathrm{sp}}$ for a single polymer is measured as a function of temperature, as shown in Figure 14. The modulus increases as the temperature decreases, making the polymer progressively less compressive and therefore having less free volume. The dependence of $P_{\mathrm{sp}}$ on pressure becomes more linear as the temperature decreases, as evidenced by the $P_{\text {sp }}$ values.

Table 3. Dependence of specific permeability on temperature for extrusion molded HDPE.

\begin{tabular}{cc}
\hline $\begin{array}{c}\text { Temperature } \\
\left({ }^{\circ} \mathbf{C}\right)\end{array}$ & $\begin{array}{c}\text { Pressure dependence of } \boldsymbol{P}_{\mathbf{s p}} \\
\left(\mathbf{m o l ~} \mathbf{H}_{\mathbf{2}} \cdot \mathbf{m} / \mathbf{m}^{\mathbf{2}} \cdot \mathbf{s} / \mathbf{k P a}\right)\end{array}$ \\
\hline 85 & $0.89[0.03]$ \\
23 & $0.90[0.04]$ \\
5 & $0.92[0.05]$ \\
-15 & $0.96[0.06]$ \\
\hline \hline
\end{tabular}

The standard error for each dependency is shown in square brackets. 


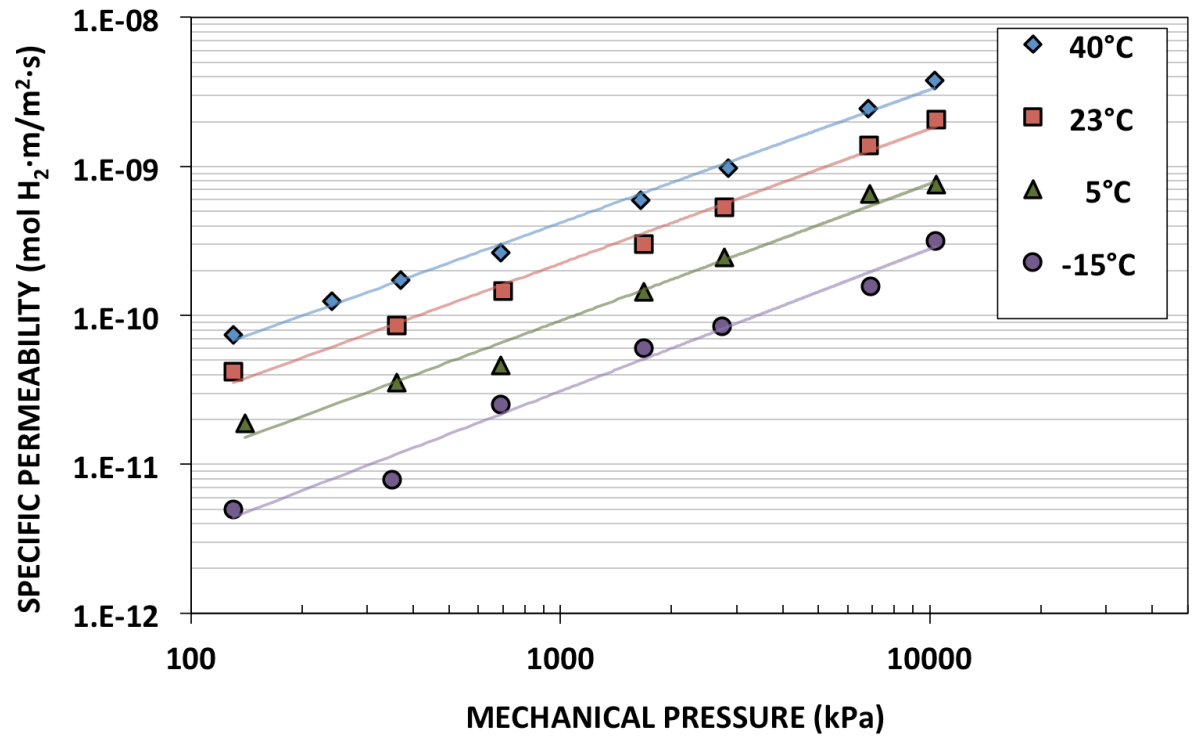

Figure 14. Pressure dependencies of a specimen of extrusion molded HDPE, measured at multiple temperatures. 


\section{CONCLUSIONS AND FUTURE DIRECTIONS}

The measurements of hydrogen permeabilities for several polymers in current use as tank liners-or being proposed for future use for such applications-show that the polymers have permeabilities that differ by an order of magnitude or less. The activation energies measured over the temperature range -30 to $85{ }^{\circ} \mathrm{C}$ were very closely grouped around $31 \mathrm{~kJ} / \mathrm{mol}$, the exception being the specimen of compression molded TLCP which had an activation energy of $19.5 \mathrm{~kJ} / \mathrm{mol}$. All the polymers show promise as good hydrogen barrier materials, based on their permeability coefficient values. The TLCP exhibited a significant amount of pressure-induced creep when subjected to prolonged temperatures above room temperature. Additional evaluation of the high-pressure stress behavior of TLCP is in order before it can be qualified as a realistic barrier material candidate.

Unforeseen delays brought about by instrumentation problems in the temperature cycling apparatus delayed completion of the lifecycle durability measurements. Our intent is to complete measurements on as many polymers as possible and to publish the test procedure along with the durability measurements.

The use of disc specimens for the durability measurements is a useful screening method, but this methodology might not be sufficient for predicting the performance of polymer liners in actual systems. Liners in tank systems will be exposed to flexural and tensile conditions in addition to those brought about by thermal cycling, and interactions of the liner with the surrounding walls will add to the complexity of a real-world evaluation of the liner's durability.

A test methodology that incorporates an in toto temperature cycling evaluation of tank liner in contact with the composite reinforcement would

- Provide a fuller understanding of how liners function when situated in proximity to the composite reinforcement,

- Address the issue of absorption of $\mathrm{H}_{2}$ in the liner and the subsequent volumetric expansion of the liner or pressurization of the void between the liner and reinforcement layers, and how these conditions could pose a concern for delamination during rapid depressurization of the tank, and

- Provide a direct measurement of tank liner leakage as a function of cycle life

Additional future work, which is also beyond the scope of the current project, should address the impact of rapid depressurization on the liner and perform a number of temperature cycling and permeation measurements using $\mathrm{H}_{2}$ incorporating concentrations of likely contaminants.

Future research should focus on measurements on additional tank liner materials, primarily those that promise to be significantly less expensive and with lower hydrogen permeation. Future research should focus on an investigation of the durability of the tank liners when they are in physical contact with the reinforcement structure in toto. It is widely known by manufacturers of Type IV composite tanks that the liner permeability of the tank liner tends to be significantly less in practice than predicted based on permeation coefficients and liner thickness. The fiber-epoxy reinforcement, which is the structural support for the liner, appears to enhance the liner's ability to retain hydrogen at high pressures. To adequately assess this contribution and to determine whether it persists during temperature cycling requires a lifecycle analysis of the structure. 
ORNL/TM-2014/48

\section{INTERNAL DISTRIBUTION}

1. Lawrence M. Anovitz

2. D. Barton Smith
3. David L. Wood, III

4. ORNL Office of Technical Information

\section{EXTERNAL DISTRIBUTION}

5. Grace Ordaz, Technology Development Manager, Fuel Cell Technologies Office, Office of Energy Efficiency and Renewable Energy, United States Department of Energy

6. Ned T. Stetson, Hydrogen Storage Team Leader, Fuel Cell Technologies Office, Office of Energy Efficiency and Renewable Energy, United States Department of Energy 